\title{
Genetic Variability Among Maize Inbred Lines for Resistance to the High Plains Virus-Wheat Streak Mosaic Virus Complex
}

A. Marçon, Research Graduate Student, University of Nebraska-Lincoln, Department of Agronomy, Lincoln 68583-0915; S. M. Kaeppler, Assistant Professor, University of Wisconsin, Department of Agronomy, Madison 53706-1597; and S. G. Jensen, USDA-ARS, Wheat, Sorghum, and Forage Research Unit, Lincoln, NE 68583-0722

\begin{abstract}
Marçon, A., Kaeppler, S. M., and Jensen, S. G. 1997. Genetic variability among maize inbred lines for resistance to the high plains virus-wheat streak mosaic virus complex. Plant Dis. 81:195-198

High plains virus (HPV) is a pathogen that causes a severe disease, especially in susceptible corn genotypes. The virus is transmitted by the eriophyid mite Aceria tosichella, which also transmits wheat streak mosaic virus (WSMV). This often results in a mixed infection by these two viruses. Genetic variability for resistance to the HPV exists among maize inbred lines but has not been characterized. The disease reaction of 30 maize inbred lines to the mixed infection and to WSMV alone was characterized in this study. Evaluation was based on symptom expression and virus titer (HPV and WSMV), as measured by enzyme-linked immunosorbent assay. All lines showed some HPV symptoms, which ranged from a few visible spots to rapid plant death. HPV-resistant inbreds include B73 and B14. Susceptible inbreds include W64A, Wf9, H100, N213, N215, and N194. Five of the six inbreds most severely affected by HPV also had a high WSMV titer, although they displayed few symptoms when inoculated with WSMV alone. Inbred N194 was one of the genotypes most susceptible to HPV, but it showed no detectable WSMV titer. Seedlings of highly susceptible genotypes often died within 2 weeks of infection.
\end{abstract}

High plains virus (HPV) is a newly discovered virus that infects a number of monocots, including maize and wheat $(4,7,10)$. Preliminary reports of the molecular biology of the virus have been published $(8,9,11)$. The virus has an associated $32-\mathrm{kDa}$ protein, which is probably an nprotein rather than a capsid protein. Five species of dsRNA have been consistently recovered from viral nucleoproteins purified from infected maize and wheat. The ultrastructure of HPV-infected cells has been described $(1,2)$, and it resembles the ultrastructure of cells infected with rose rosette, redbud yellow ringspot, fig mosaic, and thistle mosaic pathogens. Viroplasms and large ovoid to spherical double membrane bound bodies $150 \mathrm{~nm}$ in diameter characterize the infected cells. Symptoms of the disease are very severe in susceptible genotypes, killing maize plants in as little as 2 weeks following infection, de-

Corresponding author: S. M. Kaeppler

E-mail: smkaeppl@facstaff.misc.edu

Contribution 11417 from the Nebraska Agricultural Experiment Station. Research was supported in part by the Center of Biotechnology, University of Nebraska-Lincoln.

Accepted for publication 8 November 1996.

Publication no. D-1996-1217-06R

This article is in the public domain and not copyrightable. It may be freely reprinted with customary crediting of the source. The American Phytopathological Society, 1997. pending on time of infection and environmental conditions. The disease, identified in the summer of 1993 in several high plains states, produces interveinal chlorotic lesions, which are often most severe on lower leaves and leaf tips. Since 1993, it has been found with increasing frequency over a much wider area, probably due to greater awareness and surveillance.

Symptoms of HPV are similar to the symptoms described in plants affected by wheat spot mosaic virus (WSpMV) (21) and wheat spot chlorosis pathogen (WSpCP) (17). Similarities between WSpMV or WSpCP and HPV include transmission by an eriophyid mite, spherical double membrane bound bodies in the cytoplasm (11), host range, and characteristic chlorotic spots (21). Cultures of these pathogens are no longer available, so actual identity or similarity cannot be determined. The wide geographic range distribution of HPV suggests that it has been around for a long time.

HPV is obligately transmitted by the eriophyid mite Aceria tosichella Keifer (D. Seifers and T. Harvey, personal communication), which is also the vector of wheat streak mosaic virus (WSMV) $(3,20)$. Under field conditions, plants are infected by both HPV and WSMV. Evaluation of maize reactions to these viruses was conducted using viruliferous mites carrying both viruses, because the mixed infection best approximated field infection, and also because a mite colony transmitting only HPV has not yet been maintained.
No reports are currently available on genetic variation among corn lines for tolerance to HPV. Tolerance to WSMV is more extensively characterized $(15,16)$. In general, corn shows few symptoms when infected with WSMV. Resistance to the disease involves inhibition of systemic spread of the virus, and loci responsible for resistance have been mapped $(15,16)$. The goal of this research was to define genetic variation for resistance of maize inbred lines to the HPV-WSMV disease complex. The lines represented a diverse array of genetic backgrounds, including genotypes of historic importance in maize production.

\section{MATERIALS AND METHODS}

Thirty genotypes of yellow dent maize were tested (Table 1). The experimental unit consisted of five seeds of a genotype sown in a $15-\mathrm{cm}$-diameter pot. Seeds were germinated in the glasshouse, and seedlings were transferred to a growth chamber for virus inoculation by mites when the third leaf began to emerge from the whorl. The mite colony maintained on wheat carried both HPV and WSMV, as determined by enzyme-linked immunosorbent assay (ELISA) as described by Clark and Adams (5). Pots of wheat and maize were arranged so that each pot of maize touched at least one pot of mite-infested wheat. After 5 days in the growth chamber, the maize was sprayed with a miticide and transferred to the glasshouse. The growth chamber was maintained at $27^{\circ} \mathrm{C}$ and approximately $70 \%$ humidity with $500 \mu \mathrm{E} / \mathrm{m}^{2} / \mathrm{s}$ of light. The glasshouse was maintained at approximately $27^{\circ} \mathrm{C}$ daytime and $21^{\circ} \mathrm{C}$ nighttime temperature. Both areas received $16 \mathrm{~h}$ of light.

Four experiments were conducted. One experimental unit of five plants per pot was used for each treatment in experiments 1 , 2 , and 4; and two pots per treatment were used in experiment 3 . In estimating the disease reaction, each of the five plants within a pot was scored separately, and the mean score was given to the experimental unit. Each genotype was tested in at least three experiments.

Ratings of disease severity were done 2 to 3 weeks after the plants were infested with mites carrying viruses. The rating scale was based on criteria observed for symptomatology on lower leaves and systemic spread of the virus to upper leaves. For symptomatology, the lower four to five 
leaves were rated on a scale of 1 to 4 where 1 = no spots observed; 2 = few visible chlorotic spots; 3 = chlorotic spots coalescing, large areas of chlorotic lesions; and 4 = advancing necrosis and leaf death. For systemic symptomatology on the upper leaves, we used a scale of 1 to 3 where $1=$ no induced systemic symptoms; 2 = moderate spread; and 3 = rapid spread. Rate of systemic spread was determined by the expression of symptoms on upper, newly emerging leaves. These upper leaves were the eighth or higher at the time of reading and would not have been available for direct inoculation by mite feeding.

Mechanical inoculation of all genotypes with WSMV alone allowed the effect of WSMV to be separated from the effect of the mixed infection. Genotypes were inoculated with WSMV only, using an isolate called AM strain, and also with the WSMV-Sidney strain. WSMV-AM was isolated from wheat with the mite colony and HPV; WSMV-Sidney is a typical Nebraskan strain. Five plants of each genotype were grown in containers and mechanically inoculated in the three-leaf stage (13). When the tassel began to emerge, the uppermost leaf was sampled for ELISA. Virus detection for all virus treatments was based on the double antibody sandwich technique (DAS-ELISA). Detection of HPV was based on indirect ELISA. The antiserum for this analysis was raised in a rabbit by a series of three injections of 1 $\mathrm{mg}$ each of the $32-\mathrm{kDa}$ nucleoprotein purified from field-infected maize. The antiserum was harvested 3 months after the initial injection, when the antiserum reached maximum titer (11). It also carried some reaction with WSMV and required cross absorption with WSMV-infected plant sap before use. After cross absorption of the antiserum, there was no reaction against healthy or WSMV plant sap at a dilution of 1:4. An upper leaf subjected only to systemic infection was taken from each plant in a treatment, and all leaves from a pot were pooled for ELISA. The leaves were confined in a 2-mil plastic sleeve, and the sap was expressed in a roller press. The sap was diluted 1:4 for WSMV and 1:10 for HPV before loading onto ELISA plates for assay. ELISA values greater than twice the respective uninoculated controls were considered positive based on establishment of positive-negative threshold in our samples and on suggestions by Sutula et al. (22). Known negative and positive controls were included in each assay to ensure representation of known values. Controls were replicated in each assay at least twice.

Data from the HPV study were analyzed using ProcGLM (19). Replicates and plants in replicates and genotypes were considered random effects. Least-square means were computed. Differences among means for the rating score were compared using least significant difference, computed for each comparison due to the unbalanced data set. Genetic background response differences to the disease involving groups of Stiff Stalk Synthetic and groups of lines derived from other heterotic groups were analyzed by SAS-GLM contrast procedure (19).

\section{RESULTS AND DISCUSSION}

Resistance to HPV was identified among maize inbred lines. It was observed that the five plants in a pot representing a genotype gave highly uniform reactions, indicating that the inoculation procedure was efficient and the inoculation challenge was uniform.

Table 1. Effects of high plains virus (HPV) and wheat streak mosaic virus (WSMV) on systemic spread, symptomatology, and virus titer as measured by enzyme-linked immunosorbent assay (ELISA) ${ }^{\mathrm{x}}$ of maize genotypes challenged with mites carrying HPV and WSMV, and the same genotypes mechanically inoculated with WSMV (AM isolate and Sidney strain)

\begin{tabular}{|c|c|c|c|c|c|c|c|c|}
\hline & & \multicolumn{5}{|c|}{ HPV-double complex infection (mite as vector) } & \multirow{2}{*}{\multicolumn{2}{|c|}{$\begin{array}{c}\text { WSMV(mechanical inoculation) } \\
\text { ELISA score }\end{array}$}} \\
\hline & & \multirow[b]{2}{*}{$\mathbf{n}^{\mathbf{y}}$} & \multicolumn{2}{|c|}{ Symptom score } & \multicolumn{2}{|c|}{ ELISA score } & & \\
\hline & & & S-score ${ }^{\mathrm{z}}$ & L-score ${ }^{\mathrm{z}}$ & HPV & WSMV-AM & WSMV-AM & WSMV-Sidney \\
\hline B14 & Iowa S.S. Synth. & 24 & 1.00 & 1.94 & 0.31 & 0.31 & 0.12 & 0.29 \\
\hline B37 & Iowa S.S. Synth. & 23 & 1.34 & 3.09 & 0.50 & 0.23 & 0.30 & 0.13 \\
\hline B73 & Iowa S.S. Synth. & 24 & 1.00 & 1.96 & 0.16 & 0.18 & 0.16 & 0.15 \\
\hline B79 & Iowa T.E. Synth. & 23 & 1.80 & 3.11 & 1.14 & 2.00 & 1.25 & 1.76 \\
\hline B84 & Iowa S.S. Synth. & 24 & 1.29 & 2.40 & 0.82 & 0.30 & 0.15 & 0.16 \\
\hline H100 & $\mathrm{N} 28 \times \mathrm{H} 91$ & 23 & 2.56 & 3.56 & 2.00 & 0.60 & 1.14 & 1.86 \\
\hline Mo17 & CI187-2 × C103 & 24 & 1.56 & 2.81 & 0.28 & 0.17 & NT & 0.12 \\
\hline Mo44 & Mo22 × Pioneer Mex.17 & 20 & 1.92 & 2.84 & 1.18 & 0.52 & NT & 1.87 \\
\hline N190 & CM105 × B73 & 19 & 1.15 & 1.87 & 0.27 & NT & NT & 0.17 \\
\hline N192 & CM105 × B73 & 19 & 1.11 & 2.21 & 0.16 & 0.18 & 0.12 & 0.13 \\
\hline N193 & Krug & 18 & 2.47 & 3.42 & 1.96 & 0.18 & 0.12 & 0.14 \\
\hline N194 & Krug & 23 & 2.83 & 3.76 & 2.00 & 0.20 & 0.12 & 0.19 \\
\hline N197 & (Mo17 × Krug)Mo17 & 20 & 1.65 & 3.18 & NT & 0.18 & NT & 0.15 \\
\hline N199 & Mo44 & 17 & 1.41 & 1.91 & 1.07 & 0.61 & 0.13 & 0.17 \\
\hline N200 & Mo44 & 20 & 1.13 & 2.18 & 0.39 & 0.57 & 0.18 & 0.13 \\
\hline N201 & $\mathrm{N} 28 \times \mathrm{B} 73$ & 20 & 1.00 & 1.67 & 0.16 & 0.14 & 0.15 & 0.12 \\
\hline N205 & Nebraska B Synth. & 25 & 1.10 & 2.12 & 0.87 & 0.19 & 0.14 & 0.12 \\
\hline N209 & Nebraska S.S. Synth. & 25 & 1.02 & 2.08 & 0.16 & 0.20 & 0.13 & 0.16 \\
\hline N211 & Nebraska CLNA Synth. & 23 & 1.02 & 2.08 & 0.18 & 0.21 & 0.16 & 0.16 \\
\hline $\mathrm{N} 212 \mathrm{~A}$ & Nebraska R. Synth. & 17 & 1.00 & 1.94 & 0.19 & 0.20 & 0.12 & 0.27 \\
\hline $\mathrm{N} 212 \mathrm{~B}$ & Nebraska R. Synth. & 16 & 1.31 & 2.75 & 0.16 & 0.16 & NT & 0.13 \\
\hline N213 & Nebraska R. Synth. & 13 & 2.85 & 3.96 & 2.00 & 2.00 & 1.35 & 0.67 \\
\hline N215 & Nebraska B Synth. & 23 & 2.43 & 3.41 & 0.78 & 2.00 & 1.65 & 1.99 \\
\hline N217 & Nebraska CLNB Synth. & 18 & 1.06 & 1.87 & 0.16 & 0.14 & 0.14 & 0.18 \\
\hline N218 & Nebraska CLNB Synth. & 19 & 1.00 & 1.89 & 0.16 & 0.15 & 0.16 & 0.14 \\
\hline N219 & Nebraska CLNA Synth. & 18 & 1.31 & 2.44 & 0.24 & 0.14 & 0.13 & 0.32 \\
\hline Oh43 & Oh40B $\times$ W8 & 24 & 1.88 & 2.87 & 0.91 & 2.00 & NT & 1.64 \\
\hline $\mathrm{Pa} 405$ & $\mathrm{NY} 3 \times \mathrm{Pa} 54$ & 20 & 1.30 & 2.68 & 0.16 & 0.15 & 0.12 & 0.21 \\
\hline Wf9 & Wilson Farm Reid & 25 & 2.72 & 3.34 & 1.19 & 2.00 & 1.99 & 1.69 \\
\hline W64A & Wf9 $\times$ CI187-2 & 24 & 2.96 & 3.85 & 1.60 & 2.00 & 1.75 & 1.82 \\
\hline
\end{tabular}

${ }^{\mathrm{x}}$ ELISA values $\left(A_{405 \mathrm{~nm}}\right)$ were considered positive if twice those of healthy control. Uninoculated control, ELISA range 0.12 to 0.15 . WSMV-expressed plant sap diluted 1:4. HPV-expressed plant sap diluted 1:10.

${ }^{y}$ Number of plants tested. NT $=$ not tested.

${ }^{\mathrm{z}}$ Systemic spread (S-score), based on a scale of 1 to 3, was estimated by the rate and extent of symptom development on upper, newly emerging leaves. 1 $=$ no visual evidence of virus spread; $2=$ systemic spread slow with moderate symptoms; 3 = rapid systemic spread with moderate to severe symptoms. Symptomatology of the lower leaves (L-score) was based on a 1 to 4 scale. $1=$ no symptoms observed; $2=$ few or mild symptoms; $3=$ moderate to severe chlorotic lesions, no necrosis; 4 = severe chlorosis, leaf margin necrosis, advanced necrosis, and plant death. 
Replication effects were not significant, indicating that the results were repeatable from experiment to experiment; variation among genotypes was highly significant (Tables 2 and 3). Results from growth chamber-greenhouse studies were generally consistent with field observations in resistance or susceptibility ratings (A. Marçon, S. M. Kaeppler, and S. G. Jensen,

Systemic spread of the high plains virus did not occur rapidly or at all in many of the genotypes used in this study (Table 1). HPV symptoms appeared on the lower leaves of all genotypes, but the upper less. Systemic spread of the virus appears to be important in the severity of the disease and potential crop yield loss, especially when plants are inoculated as seedlings. Casual observations in the field could be biased, because many genotypes may have shown symptoms at an early growth stage, but the disease did not spread systemically, thus giving older plants a generally healthy appearance. seedlings, and in many genotypes the most severe symptoms were observed on the lower leaves. The differential response of genotypes was clear, with some seedlings of susceptible genotypes being killed in as few as 8 days (e.g., N194 and W64A), while seedlings of resistant genotypes were free of symptoms in upper leaves of the plant in the same time. Genetic variation in lesion size was evident, indicating a differsion size at the point of infection showed no obvious relationship with systemic virus movement. Rapid systemic spread of the Spread of the virus throughout the plant is likely of most practical importance for agronomic production. The genotypes most severely infected generally had severe symptoms on the lower leaves, but more importantly, they had the most rapid development of systemic infection on the upper leaves. unpublished). leaves of many genotypes were symptom-

The plants in this study were infected as ential response in local virus spread. Levirus resulted in plant stunting and death.

Five of the six genotypes most severely infected by HPV were also susceptible to WSMV when mechanically inoculated (Table 1). However, N194 was susceptible to HPV but showed no detectable WSMV titer in single-virus infection by mechanical inoculation or in the mixed infection following mite transmission. Possible interactions of HPV and WSMV are only speculation at this point, because a culture of HPV alone is not currently available. However, several observations can be made. First, HPV can kill genotypes such as N194, which contain little if any WSMV. Second, WSMV symptoms were not severe in the genotypes most susceptible to HPV (W64A, H100, and Wf9) when inoculated with WSMV alone. WSMV infection alone was not severe enough in any corn genotype to cause plant death or tissue necrosis even though inbreds W64A, Wf9, N215, and B79 had high ELISA readings. Therefore, HPV is the critical component leading to rapid plant death observed on these genotypes when challenged with both viruses. Interactions among two variable virus genotypes and a variable host genotype complicate scoring of field plants carrying both viruses. W64A, for example, had very mild symptoms with WSMV-Sidney but more obvious symptoms with WSMV-AM.

Substantial genetic variation exists among corn genotypes for the number and size of HPV lesions and the rate of virus systemic spread to newly emerging tissues. We observed that some corn genotypes that are most severely affected are probably highly susceptible to HPV, and symptom development is compounded by susceptibility to WSMV. The two viruses may interact to increase the titer of one or both, similar to sugarcane mosaic virus (strain MD-B) and maize chlorotic mottle virus in the corn lethal necrosis disease $(6,18)$. However, preliminary trials suggest that the titer of WSMV is lower in the mixed infection than with WSMV alone (data not shown). It may be that the two viruses damage the cells in ways such that the

Table 2. Analysis of variance for 30 maize genotypes challenged with the high plains virus complex. Results are based on localized rating system. All genotypes were evaluated in at least three replicates

\begin{tabular}{lrccc}
\hline Source & df & Mean square & $\boldsymbol{F}$ value & $\boldsymbol{P}>\boldsymbol{F}$ \\
\hline Replicates & 4 & 0.125 & 0.72 & 0.637 \\
Plants in replicates & 20 & 0.195 & 1.12 & 0.320 \\
Genotypes & 29 & 9.862 & 56.72 & 0.0001 \\
Residual & 583 & 0.174 & & \\
Total & 636 & & & \\
\hline
\end{tabular}

Table 3. Analysis of variance for 30 maize genotypes challenged with the high plains virus complex. Results are based on systemic rating system. All genotypes were evaluated in at least three replicates

\begin{tabular}{lrccc}
\hline Source & df & Mean square & $\boldsymbol{F}$ value & $\boldsymbol{P}>\boldsymbol{F}$ \\
\hline Replicates & 4 & 0.208 & 1.49 & 0.203 \\
Plants in replicates & 20 & 0.057 & 0.41 & 0.989 \\
Genotypes & 29 & 9.465 & 67.78 & 0.0001 \\
Residual & 582 & 0.139 & & \\
Total & 635 & & & \\
\hline
\end{tabular}

results are additive and lethal. Symptoms of HPV are most evident on the tips and blades of lower leaves; whereas symptoms of WSMV are most evident on the base of newly emerging upper leaves. Together, the two diseases affect most of the exposed leaf tissue of susceptible genotypes.

HPV is a devastating virus in susceptible corn genotypes. Fortunately, many dent corn genotypes are relatively resistant to the disease complex. Lines with systemic movement scores of 1.5 or less (Table 1) would be considered resistant to this virus. The relative resistance of many dent corn hybrids to the disease may be explained, in part, by the good resistance of B14 and B73. These inbreds are progenitors of numerous parental lines, and derivatives of both $\mathrm{B} 14$ and B73 are common parental lines in many commercial hybrids. Similar ratings between related lines (e.g., B73, N190, N192, N201 or Wf9, and W64A) suggest that a small number of genes with large effects may be involved in disease response. Our preliminary analysis of segregating populations (unpublished) supports this contention; however, more extensive research is necessary to characterize gene number and effect. Field surveys and screening nurseries show that although many currently grown dent corn hybrids show good tolerance to the disease, a number of sweet corn hybrids show high susceptibility (8).

Significant differences based on ELISA and systemic spread $(P r .>F=0.001)$ were found comparing Stiff Stalk Synthetic and lines derived from other corn heterotic groups. This result suggests that lines selected on the basis of diverse genetic background have significant impact on hybrids developed for HPV disease resistance. Characterization and culture of corn hybrids resistant to HPV and WSMV will be especially important in areas where winter wheat and corn are grown together, as mite transmission of these viruses to corn and back to wheat will maintain the disease cycle. Future research includes characterization of the HPV complex and of chromosome regions controlling resistance to HPV (12). Characterization of potential interactions between HPV and WSMV is important. This paper provides initial data on genetic variation for resistance to the HPV complex. Elucidation of the number, effect, and genetic location of genes controlling tolerance to HPV will enhance breeding efforts for plant protection against HPV.

\section{ACKNOWLEDGMENTS}

This work was supported in part by the University of Nebraska-Lincoln, Center for Biotechnology. Appreciation is expressed to Jeffrey Hall, Dana D. Galusha, and Chuck Papa for their help in the maintenance of mite colonies, seeds, and support throughout the development of this research.

\section{LITERATURE CITED}

1. Ahn, K.-K., Jensen, S. G., Anderson, E. J., Gergerich, R. C., and Kim, K. S. 1995. A vi- 
rus-like disease of corn and wheat in the High Plains: Ultrastructural aspects. (Abstr.) Phytopathology 85:1183.

2. Ahn, K. K., Kim, K. S., Gergerich, R. C., Jensen, S. G., and Anderson, E. J. 1996. Comparative ultrastructure of double membrane-bound particles and inclusions associated with eriophyid mite-borne plant diseases of unknown etiology: A potentially new group of plant viruses. J. Submicroscopic Cytol. Pathol. In press.

3. Brakke, M. K 1971. Wheat streak mosaic virus. CMI/AAB Descriptions of Plant Viruses, No. 48. Commonw. Mycol. Inst./Assoc. Appl. Biol., Kew, England.

4. Brown, W. M., Jr., French, R. C., Hammond, R. W., and Jensen, S. G. 1994. Occurrence and distribution of wheat viruses in Colorado. (Abstr.) Phytopathology 84:1167.

5. Clark, M. F., and Adams, A. N. 1977. Characteristics of the micro plate method of enzyme-linked immunosorbent assay for detection of plant viruses. J. Gen. Virol. 34:475-483.

6. Goldberg, K.-B., and Brakke, M. K. 1987. Concentration of maize chlorotic mottle virus increased in mixed infections with maize dwarf mosaic virus, strain B. Phytopathology 77:162-167

7. Jardine, D. J., Bowden, R. L., and Jensen, S.
G. 1994. A new virus of corn and wheat in western Kansas. (Abstr.) Phytopathology 84:1117-1118.

8. Jensen, S. G. 1994. The High Plains virus - a new threat to corn and wheat production in the west. Proc. Annu. Corn Sorghum Ind. Res. Conf., 49th. pp. 156-164.

9. Jensen, S. G., and Hall, J. S. 1995. Molecular characterization of a viral pathogen infecting maize and wheat in the high plains. (Abstr.) Phytopathology 85:1211.

10. Jensen, S. G., and Lane, L. C. 1994. A new virus disease of corn and wheat in the High Plains. (Abstr.) Phytopathology 84:1158.

11. Jensen, S. G., Lane, L. C., and Seifers, D. L. 1996. A new disease of maize and wheat in the high plains. Plant Dis. 80:1387-1390.

12. Marçon, A., Kaeppler, S. M., and Jensen, S. G. 1995. Inheritance of tolerance to the High Plains virus (HPV) complex in corn. Agron. Abstr. 175-176.

13. McKinney, H. H. 1949. Virus isolates from mosaic wheat in the hard red winter wheat area. Plant Dis. Rep. 33:346-349.

14. McKinney, H. H. 1949. Tests of varieties of wheat, barley, oats, and corn for reaction to wheat streak mosaic viruses. Plant Dis. Rep. 33:359-369.

15. McMullen, M. D., Jones, M. W., Simcox, K.
D., and Louie, R. 1994. Three genetic loci control resistance to wheat streak mosaic virus in the maize inbred $\mathrm{Pa}$ 405. Mol. PlantMicrobe Interact. 7:708-712.

16. McMullen, M. D., and Louie, R. 1991. Identification of a gene for resistance to wheat streak mosaic virus in maize. Phytopathology 81:624-627.

17. Nault, L. R., Styer, W. E., Gordon, D. T., Bradfute, O. E., Lafever, H. N., and Williams, L. E. 1969. An eriophyid-borne pathogen from Ohio, and its relation to wheat spot mosaic virus. Plant. Dis. Rep. 54:156-160.

18. Niblett, C. L., and Claflin, L. E. 1978. Corn lethal necrosis - a new virus disease of corn in Kansas. Plant Dis. Rep. 62:15-198.

19. SAS Institute. 1985. SAS User's Guide: Statistics. Version 5 ed. SAS Institute, Cary, NC.

20. Slykhuis, J. T. 1953. Wheat streak in Alberta and factors related to its spread. Can. J. Agric. Sci. 33:195-197.

21. Slykhuis, J. T. 1956. Wheat spot mosaic, caused by a mite transmitted virus associated with wheat streak mosaic virus. Phytopathology 46:682-687.

22. Sutula, C. L., Gillett, J. M., Morrissey, S. M. and Ramsdell, D. C. 1986. Interpreting ELISA data and establishing the positivenegative threshold. Plant Dis. 70:722-726. 